становилось избыточным, редуцировалось до отдельных цитат в курсе истории педагогики.

Философрия XX-XXI вв. продолжает осмыслять детство и ребенка, обращаясь к его аксиологии и экзистенциальности, выявляя истину его данности и истину его возможной будущности, оправдывая его, давая ему шанс состояться во взрослости. Она готова к сотрудничеству с научным знанием о человеке в единстве всех его возрастов.

1. Максапетян А. Г. Модели мира в семиотическом аспекте // Herald of the Social Sciences : [сайт]. URL: http://lraber. asj-oa.am/120/1/2003-1(48).pdf (дата обращения: 12.03.2020).

2. Барбан Е. С. Джазовые опыты // Jazz-квадрат : [сайт]. URL: https://jazzquad.ru/index.pl?act=PRODUCT\&id=102 (дата обращения: 12.03.2020).

3. Кураева Л. Г. Детство как социокультурная ценность : дис. ... канд. социол. наук. Саратов, 1995. 153 с.

4. Кислов А. Г. Оправдание детства: от нравов к праву. Екатеринбург : Изд-во РГППУ, 2002. 164 с.

5. Нефедова Л. К. Феномен детства в основных формах его репрезентации : дис. ... д-ра фрилос. наук. Омск, 2005. 337 с.

6. Гераклит // Фрагменты ранних греческих философов. М. : Наука, 1989. С. 176-257.

7. Диоген Лаэртский. О жизни, учениях и изречениях знаменитых философов. М. : Мысль, 1986. 571 с.

УДК 177

Науч. спец. 09.00.13

DOI: $10.36809 / 2309-9380-2020-27-40-44$

\section{ПЕШКОМ ПО ГОРОДУ С М. ДЕ СЕРТО, ИЛИ ИНСТРУКЦИЯ ПО ВЫЖИВАНИЮ ДЛЯ ГОРОДСКОГО АВТОСТОПЩИКА}

Статья посвящена изучению аксиологии городского жителя, отраженной в визуально-семиотических фигурах городских маршрутов. Актуальность исследований ценностной идентичности горожанина обоснована полиморфизмом городской среды как палимпсеста, заключающего наслоения гетерогенных кодов, непрерывно реструктурирующих социальный выбор. Представляя горожанина как читателя, противопоставленного Письму города, организованного текстуально, автор предлагает набор лайфххаков, выступающих диспозитивами организации жизненного опыта в пространстве города. Целью статьи является определение человекосохраняющих тактик антиподчинения городского читателя, погруженного в поле властных стратегий Письма в визуально-семиотическом ряде повседневных практик. Презюмируя город как поле стратегий подчинения и тактик уклонения, автор задает маршруты, отражающие повседневный опыт горожанина. Отдавая предпочтение маршруту перед картой как субъективному способу освоения пространства, он визуализирует динамику жизни в городской среде.

Ключевые слова: человек, город, маршрут, идентичность, ценность, политическое.
8. Платон. Государство // Древнегреческая фрилософия от Платона до Аристотеля. М. : АСТ ; Харьков : Фолио, 2003. С. 91-438.

9. Платон. Пир // Древнегреческая философия от Платона до Аристотеля. М. : АСТ ; Харьков : Фолио, 2003. С. 50-69.

10. Юнг К. Г. Божественный ребенок // Божественный ребенок: Аналитическая психология и воспитание. М. : АСТ, 1997. С. 345-381.

11. Гаспаров М. Об античной поэзии. СПб. : Азбука, 2000. $480 \mathrm{c}$.

12. Эразм Роттердамский. Воспитание христианского государя. М. : Мысль, 2001. 362 с.

13. Монтень М. Опыты : в 3 кн. М. : АСТ ; Харьков : Фолио, 2002. Кн. І. 624 с.

14. Локк Д. Избранные философские произведения : в 2 т. М. : Соцэгиз, 1960. Т. 2. 532 с.

15. Руссо Ж.-Ж. Педагогические сочинения : в 2 т. Т. 1. Эмиль, или О воспитании. М. : Педагогика, 1981. 656 с.

16. Гельвеций К. А. Об уме // Соч. : в 2 т. М. : Мысль, 1971. T. 1. С. $143-607$.

17. Шопенгауэр А. Афоризмы житейской мудрости. М. : Сов. писатель, 1990. 230 с.

18. Кант И. Антропология с прагматической точки зрения. СПб. : Наука, 1999. 472 с.

19. Сенека Л. А. Нравственные письма к Луцилию. М. : Наука, 1977. 384 с.

(C) Нефёдова Л. К., 2020

\title{
WALKING WITH M. de CERTEAU OR SURVIVAL GUIDE FOR HITCHHIKER THROUGH THE CITY
}

The article is devoted to the study of the axiology of the urban inhabitant reflected in the visual and semiotic figures of urban routes. The relevance of studies of the value identity of the citizen is justified by the polymorphism of the urban environment as a palimpsest, enclosing layers of heterogeneous codes that continuously restructure social choice. Presenting the citizen as a reader, opposed to the Letter of the city, organized textually, the author offers a set of life hacks, acting as dispositions of the organization of life experience in the space of the city. The purpose of the article is to determine the human-preserving tactics of antisubmission of the urban reader immersed in the field of power strategies of Writing in the visual-semiotic series of everyday practices. By presuming the city as a field of submission strategies and evasion tactics the author sets routes that reflect the everyday experience of the citizen. Preferring the route over the map as a subjective way of space exploration, he visualizes the dynamics of life in the urban environment.

Keywords: person, city, route, identity, value, political. 
Прежде чем выйти из дома, вспомним призыв Д. Адамса «Не паникуй!», с которым он обращается к тем, кто начинает автостопом путешествовать по галактике. Чем современный город не галактика? Давайте согласимся, что, во-первых, современный город - это палимпсест, многократно переписанный текст. Пожалуй, любое «место - это палимпсест» $[1$, c. 328], но город - особенно. «Мне знакомо лишь что-то из присутствующего в этом пространстве. Многие, возможно, более важные основания или допущения остаются скрытыми наслоениями в этом ландшафте, который является памятью и палимпсестом» [1, с. 37]. Город — пересеченная местность в значении перекрестка дорог, культур и времен. В городе причудливо сплетено полустертое прошлое, многообразное настоящее и зарождающиеся слова будущего. Город полон порталов, уводящих в любое время.

Во-вторых, город написан правителями, политиками, полицией, архитекторами, учеными; бродячими музыкантами, художниками и собаками; работодателями, работниками по контракту и прекариями-гастарбайтерами; собственниками жилья, арендаторами и бомжами: город - это Письмо, а мы - его читатели. М. де Серто обозначает словом «письмо» «конкретную деятельность, которая состоит в создании внутри своего собственного пространства (на листе бумаги) текста, обладающего властью над тем внешним, от которого он сначала был отделен» [1, с. 242]. Роман письма «Робинзон Крузо», посвященный освоению пространства необитаемого острова письмом, буквально начатого с решения вести дневник, - миф и матрица Нового времени. До сих пор в мире не прекращается кипучая деятельность «по производству текста и производству общества как текста» [1, с. 242]. Сегодня письмо стало высокотехнологичной системой самовоспроизводства знаков, превращающей «субъектов, якобы имеющих над ней власть, в простых операторов машины письма, которая ими управляет и их использует» [1, с. 244-245]. Мир-текст пишет нас и пишется нами, но в первую очередь некоторыми из нас - хозяевами дискурса.

B-третьих, как читатели мы усердны, но не всегда понимаем замысел Союза писателей. Причин на то несколько: во-первых, город всегда старше; во-вторых, мы образованы на современный лад и в чем-то недоучки; в-третьих, мы сами писатели-эссеисты, сказочники и немного философы. Наше чтение - собственная повесть. «Читатель вносит внутрь авторского текста свои приемы получать удовольствие и свои способы присвоения: он браконьерствует в нём, переносится в него, становится в нём множественным» $[1$, c. 53]. Читая, мы играем с текстом, вкладывая в него содержание собственных мыслей и фантазий. Письмо зеркально отражается в чтении, нередко трансформируя свои императивы в диспозитивы читателя. Инородное письму пространство — мир читателя — вторгается в пространство автора текста.

Наконец, городу как диктатуре письма доступна стратегическая перспектива, читателю - партизану бетонных джунглей - тактические уловки. Если лежащая в основе политической, экономической и научной рациональности «стратегия утверждает место, которое может быть очерчено как собственное и тем самым может стать основой управления этими отношениями», то тактика «не может опираться ни на «собственное» пространство, ни, как следствие, на границу, отделяющую другого как видимую целостность» $[1$, с. 50]. Тактика вторгается в пространство другого без возможности удержать захваченный плацдарм. Городскому партизану приходится тактически постоянно манипулировать событиями, создавая из них благоприятные случаи, ведь «слабый должен постоянно обращать себе на пользу чуждые ему силы» [1, с. 50]. Удел городских читателей - «ловкие проделки, искусство делать "ходы", хитрости охотников, маневрирование, разнообразные симуляции, счастливые открытия» [1, с. 51] - смекалка «первобытного человека будущего» (Дж. Зерзан) цивилизации Письма. Kairos - благоприятный случай - попутчик городского читателя, словно по мановению волшебной палочки трансформирующего бетонную логику города в уютную колыбель жизни.

Если читатель согласен, то в путь! Стоп! Чем будем пользоваться?

Карта или маршрут? Карта паноптична и отдает предпочтение модальности наблюдения, в то время как маршрут воспринимает пространство в модальности движения. Карта позволяет разработать стратегию; маршрут гибок, пластичен и трансформируем - он годится тому, чей удел тактическая уловка. Вопрос выбора между маршрутом как дискурсивной серией операций и картой как проекцией наблюдения на плоскость - это вопрос выбора «между двумя символическими и антропологическими языками пространства» [1, с. 222]. Житель города скорее Пятница, чем Робинзон Крузо. Будем пользоваться картой, но всё-таки предпочитать будем маршруты!

Маршрут 1. На учебу. Городской читатель просто обязан быть образованным. Если Письмо стало местом жизни, то умение считать, читать и писать - обязательные навыки выживания в новой - текстуальной - среде обитания. Но и образование - Письмо. Чтобы не стать рабом механически заученного текста, следует овладеть навыками бушмена, успешно выживающего среди китов картин мира, носорогов теорий, львов идеократий и гиен новостей. Классическое образование подобно силлогистике Аристотеля. Без него никуда, но и с ним не всякая цель достижима. Силлогизм - абстрактная машина истины. «Примером часовой логической системы является аристотелевский силлогизм. Такой силлогизм является формализацией лишь небольшой части дедуктивных умозаключений, однако он господствовал в логическом мышлении на протяжении двух тысячелетий. Аристотель дал нам рецепт механической передачи истины от посылок к заключению, рецепт перехода от "Все х суть у" и "Все z суть x" к "Все z суть у" < .. > Силлогизм - весьма тривиальный механизм, который может правильно передавать данные по заранее заданному пути, однако не способен производить новые знания» [2, с. 217]. Силлогистика, как и образование ex cathedra, механистична. «Силлогизм можно представить в качестве логической "музыкальной шкатулки" или автоматической игрушки - это небольшая машина, способная передавать движение (или истину) по заранее прочерченному пути» [2, с. 231]. Профессор, укладывающий курс лекций на прокрустово ложе 
методических рекомендаций и требований надзирающих инстанций, выполняет функцию транслятора основ Письма, но ограничен в пробуждении творческого, новаторского мышления. «Логические символьные системы мы можем рассматривать в качестве небольших машин, конвейерных лент для передачи истины от одного высказывания к другому... дедуктивная логика была механизирована либо в виде часового механизма (силлогизм), либо как мотор (булева логика). Напротив, индуктивную логику невозможно столь же легко механизировать. В самом деле, механическая версия индуктивных конвейерных лент равноценна построению машины, которая может учиться на опыте» [2, с. 209]. Б. Рассел утверждал, что не встречал примеров нового знания, полученного при помощи того или иного силлогизма. Абстрактные машины истины ограничены в своей функциональности.

Так, пришли! Звонок! Внемлем Учителям Письма, но помним: без самостоятельного творческого мышления образования нет!

Маршрут 2. На работу. Цивилизация Письма рациональна, прагматична, властна. Письмо - этот метаязык власти, как и сама власть, «производит себя в каждое мгновение в любой точке или, скорее, - в любом отношении от одной точки к другой. Власть повсюду, не потому, что она всё охватывает, но потому, что она отовсюду исходит» [3, с. 193]. Сложившиеся дисциплинарные практики индивидуального подчинения и биополитические регуляторы населения пронизывают общество во всём поле социальных интеракций - от макроуровня политических институций до капиллярной микрофизики власти в любом людском сообществе. В конечном итоге сложившиеся диспозитивы подавления - эти «"мельчайшие" технические процедуры, играющие на деталях и с деталями, перераспределили пространство, сделав его оператором всеобщего "надзора"» [1, с. 43]. Пространственные практики исподволь определяют условия социальной жизни. Власть над пространством коллективна, присвоение пространства - индивидуальная практика [4, с. 136]. Однако такой микрофизике власти противопоставляется сеть антиподчинения. Составляющие её «"способы делания" образуют бесчисленное количество практик, при помощи которых пользователи заново присваивают себе пространство, организованное техниками социокультурного производства» [1, с. 43]. Подобные практики, «которые напоминают кишение микробов и множатся внутри технократических структур, одновременно искажая их функционирование за счет бесчисленных "тактик", проявляющихся в "деталях" повседневной жизни» [1, с. 44], образуют разветвленную систему бриколажа - подгонки и возвращения подконтрольного власти и системе Письма социального пространства.

«Рассеянная, тактическая и "бриколерская" изобретательность групп или индивидов, отныне оказавшихся в сетях "надзора"» [1, с. 44], проявляется в «работе на себя». «Муравьиноподобная» по масштабу работа на себя, являясь историческим продолжением тактических уловок работников прошлого, пронизывает общество. «В официальные институции проникает определенный стиль социальных обменов, стиль технической изобретательности и морального сопротивления, т. е. экономика дара (щедрости, на которую отвечают щедростью), эстетика приемов (действий художников) и этика упорства (множества способов отказываться признавать за установленным порядком статус закона, видеть в нём смысл и судьбу)» [1, с. 97]. Памятуя о том, что «нет права, которое не было бы записано на телах» [1, с. 249], работники ведут «муравьиную работу» тактического сопротивления формам превращения себя в галерных рабов. В конечном итоге дисциплинарная и биополитическая власть делает уступки, что порою превращает рабочее место в средство самовыражения и даже самореализации. Работа на себя - способ преодоления отчуждения в пространстве коллективной деятельности, центрированной на достижении конечного результата и игнорирующей человекосоразмерные характеристики труда.

Возможно ли такое? Конечно, да! Загляните, например, в компанию Semco P. Семлера! «Тейлор задолго до Форда выдвинул идею производства, где тысячи безымянных, безликих рабочих пчел выполняют неимоверно монотонные операции под постоянным неусыпным контролем. Тейлор верил, что максимальная эффективность труда достигается, когда обязанности рабочих представляют собой небольшое количество четких действий, которые тщательно отрепетированы в соответствии с особенностями их анатомии. Тейлор разбил сложный производственный процесс на многочисленные задачи, каждая из которых передавалась определенной группе рабочих. Сегментация и разделение труда, тщательно систематизированные посредством четких должностных инструкций, по мнению Тейлора, были важнейшим средством достижения максимальной производительности» [5, с. 156].

Успех компании Семлера доказал, что тейлоризм изжил себя по причине неспособности вовлекать работников в процесс осуществления деятельности компании. «Точные должностные инструкции Тейлора ограничивают потенциал рабочих и сдерживают возможности повышения разнообразия работы, что негативно сказывается на мотивации. Только подумайте, насколько лучше стали бы должностные инструкции, если бы в них было зафиксировано не только то, что делают сотрудники, но и то, что они хотят сделать.

- Дорогой мой, - несомненно, спросил бы меня Тейлор, если бы мог, - разве ваша фабрика не превратится в грандиозную неразбериху?..

Мы не верим во фрагментацию. Мы хотим, чтобы рабочие знали, что они часть целого. Мы хотим, чтобы они сами нашли лучший способ выполнять свою работу. И они, скорее всего, смогут найти намного более эффективные способы, чем Тейлор и его последователи» [5, с. 158].

Рабочий день позади! Работаем в команде и не забываем о том, что в первую очередь мы - люди, а не андроиды из сериала Westworld!

Маршрут 3. Риторика ходьбы. «Хождение пешком - это начало, отправная точка. Человек создан, чтобы ходить. Все события нашей жизни, важные и не очень, случаются, когда мы ходим среди людей. Когда мы на ногах, жизнь открывается перед нами во всем своем разнообразии» $[6$, с. 19]. Идти по городу для городского читателя то же, что говорить: наш маршрут - это серия пешеходных 
высказываний. «Акт ходьбы является для городской системы тем, чем высказывание является для языка» [1, с. 193]. Речь плохого оратора ходьбы полна клише: толчеи в метро и супермаркетах, скучных бистро, асфральтовых полей, ущелий серых новостроек, со дна которых не видно небо. Певец городских троп движется метафорически и метонимически, смещаясь в направлении ярких символов, превращающих маршрут в историю, сочиненную опытным рассказчиком. Риторика ходьбы - серия петляний, «подобных "речевым оборотам" или "стилистическим фигурам"... Искусство "закручивать" фрразу чем-то подобно искусству "прокладывать маршрут”» [1, с. 196]. Среди речевых оборотов мастеров трансгородских маршрутов господствуют синекдоха и асиндетон. «Синекдоха состоит "в использовании слова в значении, являющемся частью другого значения того же самого слова". В сущности, она обозначает часть вместо целого, которое включает её в себя... аналогичным образом, каменная постройка или холм обозначают парк в описании маршрута. Асиндетон - это фигура, состоящая в том, что опускаются соединяющие слова, союзы и наречия как внутри предложения, так и между ними. Аналогично при ходьбе эта фигура будет состоять в отборе и фрагментации преодолеваемого пространства; она перепрыгивает через связи и целые сегменты пространства, которые опускает. С этой точки зрения любая прогулка постоянно прыгает и скачет, как ребенок, "на одной ножке". Она осуществляет эллипсис связывающих мест» [1, с. 198-199]. Прыгая «на одной ножке», мы умело обходим стороной пустоши и свалки артефактов цивилизации, броуновское движение потоков машин и людей. И каждый раз случается чудо: мы обнаруживаем неожиданно-новый лик города и встречаем таких же романтиков, как мы. «На улице или площади мы можем исполнять танец общения, используя весь арсенал хореографии: подход, шаг навстречу, движения в стороны и, наконец, изящный уход со сцены» [6, с. 49].

Добрались! Ведь город написан для встреч и нам, как городским браконьерам, известны места, где происходят самые незабываемые из них!

Маршрут 4. «Эй, вы, там!» Улица инклюзивна, она вовлекает в события. Хорошо, если человека застиг врасплох уличный театр! Можно подурачиться, сменив серьезное лицо на маску клоуна. Но оклик «Эй, ты, там!» может вовлечь в неприятности. Если карнавал не требует самоидентификации, то оклик полицейского превращает прохожего в субъекта правовых отношений. Это интерпелляция, и прохожий теперь интерпеллирован, т. е. признал в себе того, к кому обращен оклик. «Суть заключается в том, что человек оборачивается, хотя он и не может знать, что полицейский обратился именно к нему, а не к кому-то другому... В результате этого простого разворота своего тела на 180 градусов он становится субъектом. Почему? Потому что он признает, что обращение адресовано "именно" ему и что "это обратились именно к нему", а не к кому-то другому». Так происходит «операция по превращению пассивных прохожих в активных участников во многом аналогично вовлечению в политику» [7, с. 93]. Вдруг беспечный читатель обнаруживает себя в деонтической и одновременно алетической модальности правовой реальности.
Оклик, однако, имеет предысторию, и связана она с логической аргументацией, а именно с демонстрацией - логической связью между аргументами и тезисом. В городе аргументация зрима: её присутствие отмечено скоплением людей - демонстрацией. Демонстрация - это демонстрация демонстрации, т. е. связи между тезисом, который всегда один и тот же и выражает «верификацию равенства» (Ж. Рансьер), и аргументами, которые каждый раз различаются и обращены к конкретному событию нарушения равенства прав и свобод.

«Политика состоит в преобразовании... пространства движения в пространство манифестации некоего субъекта.. Она заключается в реконсигурировании пространства.. Она представляет собой институционализированную тяжбу о разделении ощутимого... Эти действия надо организовать как доказательство, систему доводов... Последняя принимает новую форму демонстрации (доказательства)» $[8$, c. 210]. Улица вдруг становится символической агорой, на которой царит политическое.

Конечно, полиция, исполняя долг сохранения правопорядка, взывает к очевидности: «Проходите! Здесь не на что смотреть». Полиция говорит, что на шоссе не на что смотреть и нечего делать, кроме как проходить или проезжать. Она утверждает, что пространство движения есть пространство движения - и только» [8, с. 210]. Но суть происходящего имеет значение для всех - и для демонстрантов, и для полиции. «Превращение силовых отношений в практику демонстраций» [8, с. 77], возникшее «полемическое общее место для разбора несправедливости и демонстрации равенства» [8, с. 107], в пределах символического пространства которого «демонстрация равенства всегда привязывает силлогистическую логику или/или (граждане, человеческие существа мы или нет и т. д.) к логике паратаксиса: «мы таковы и мы не таковы» [8, с. 106], - в конечном итоге означает «торжество языка над насилием» (П. Рикер). В этом пространстве творится важное - от того, осуществится верификация равенства или нет, восторжествует справедливость или нет, зависит продолжение истории оклика «Эй, ты, там!». Если большая посылка всеобщего равенства прав и свобод была успешно сопоставлена с меньшей посылкой частного случая и в полученном заключении было подтверждено право тех, кто его был лишен, что было услышано властью, то «Эй, вы, там!» не вызовет страха и разрешится в диалоге стража Письма и читателя. Если же воплощенная фигурой скопления людей в складке урбанистики и политики логика не будет оценена по достоинству, то «Эй, ты, там!» разрешится непредсказуемым образом.

Остановимся, чтобы задуматься! Следует помнить о том, что мы все включены в процесс верификации равенства и серьезное отношение к статусу гражданина - долг, даже если читатель полагает, что его городские маршруты и пешеходные высказывания аполитичны и безопасны.

Маршрут 5. Домой! За коллизиями противоборства стратегий Письма и браконьерства чтения стоит поиск собственной идентичности. «"Идентичность” - это то, посредством чего ты чувствуешь, что ты тот же самый, независимо от места и времени, прошлого или будущего; это то, посредством чего происходит идентификация. ...Большая 


\section{ФИЛОСОФИЯ}

часть людей склонны к прочному ощущению, что они те же самые неизменные существа от утробы матери и до могилы» $[9$, с. 80]. Однако мы не рождаемся с раз и навсегда заданной идентичностью. «Другие люди становятся своего рода инструментом для идентичности, с помощью которого можно собрать по кусочкам картину себя самого. Ты узнаешь себя самого в этой привычной улыбке узнавания, которой встречает тебя этот давний друг» [9, с. 80].

Люди, наполняющие город, идентифицируют нас. Мы отражение в зеркалах города, «жизни в стеклах витрин» (В. Цой). Идентичность для себя и идентичность для других - контрпроекции, постоянно достраивающие друг друга. Тем важнее характер влияния человека на человека. «Основа человеческой жизни среди людей двуедина - это желание каждого человека быть подтвержденным другими людьми таким, как он есть, и даже каким он способен стать; а также естественная способность каждого человека подтверждать подобных себе в этом же отношении. То, что эта способность остается в огромной мере неразвитой, составляет поистине слабость и сомнительность человечества: действительно человеческое существует только там, где эта способность раскрыта» [9, с. 90]. Подтверждение либо неподтверждение - основа триумфов и драм человеческого существования. «Каждое человеческое существо, будь то ребенок или взрослый, требует определенной значительности в глазах другого, то есть места в мире какого-либо другого человека» [9, с. 122]. Но всегда ли так? Систематическое неподтверждение - печать шизофреногенных семей. Там, где человек наиболее открыт и уязвим, обнаруживается исток формирования ложного «я», калечащий человека, если не навсегда, то на долгое время. «Многолетнее отсутствие подлинного подтверждения облекается в форму активного подтверждения ложного "я", так что тем самым человек, чье ложное "я" подтверждается, а реальное не подтверждается, помещается в ложную позицию. Человеку в ложной позиции неудобно, стыдно или страшно не быть фальшивым. Подтверждение ложного "я" происходит при том, что никто в семье не имеет ясного понимания настоящего положения дел» [9, с. 92]. Ситуация Double Bind («двойного послания» или «двоякого предписания» - Г. Бейтсон) ставит жертву, не способную оценить обстановку как противоестественную, в «безвыигрышное» положение, разрушительное для личности. Подобный Double Bind - антураж кафкиансих историй об американских горках бредовых иллюзий — возможен в семье, в трудовом коллективе, в любых людских сообществах. Разрушительное неподтверждение, взращивающее ложное сознание, нарушает баланс «отнесенности и отделенности» [10, с. 26] - меры включе- ния человека в коллективное бытие и его автономии. Double Bind - «ножницеобразная» (db) фигура бесконечной $(\infty)$ разделенности (v) - визуально-семиотическая схема личностной катастрофы - провала в построении межличностной коммуникации.

Каждый из нас должен помнить, что все мы имеем право на похвалу и ошибки. Человек ошибающийся может быть прощен, человек старающийся должен быть отмечен вниманием.

Вот мы и дома! «Охана - значит семья, а в семье никогда никого не бросят и не забудут» («Лило и Стич», 2002).

Окружной путь петляний по городу - маршрут нашей жизни. Человек - странник, путник. Длина пути, комфортность путешествия, впечатления и тот истинный голос нашего «я», который порождает возглас благодарности, удивления, досады либо разочарования в конце пути, - всё это основывается на тех символах, которые стали близки нашему сердцу. Инструкция по выживанию для автостопщика по городу - скромный компендиум принципов человекосберегающих способов отношения попутчиков друг к другу.

1. Серто Мишель де. Изобретение повседневности. Кн. 1. Искусство делать / пер. с фрр. Д. Калугина, Н. Мовниной. СПб. : Изд-во Европейского ун-та в Санкт-Петербурге, 2013. $330 \mathrm{c}$.

2. Деланда М. Война в эпоху разумных машин / пер. с англ. Д. Кралечкина. Екатеринбург ; М. : Кабинетный ученый ; М. : Ин-т общегуманит. исследований, 2014. 338 с.

3. Фуко М. Воля к истоине: по ту сторону знания, власти и сексуальности. Работы разных лет : пер. с франц. М. : Касталь, 1996. 448 с.

4. Горнова Г. В. Антиномии города : моногр. Омск : Изд-во ОмГПУ, 2011. 214 с.

5. Семлер Р. Маверик : пер. с англ. М. : Добрая книга, 2007. 384 c.

6. Гейл Я. Города для людей : пер. с англ. М. : Альпина Паблишер, 2012. 276 с.

7. Модер Г. Чему Альтюссер может научить нас об уличном театре - и наоборот // Стасис. 2014. № 1. Революции и протестные движения. С. 92-104.

8. Рансьер Ж. На краю политического / пер. с фрр. Б. М. Скуратова. М. : Праксис, 2006. 240 с.

9. Лэйнг Р. Д. «Я» и Другие / пер. с англ. Е. Загородной. М. : Независимая фирма «Класс», 2002. 192 с.

10. Лейнг Р. Разделенное Я. Киев : Гос. б-ка Украины для юношества, 1995. 320 с.

(С) Попов Д. В., 2020 